\title{
Planície flúvio-marinha do Rio Grande do Norte: uma abordagem geossistêmica
}

\author{
Fluvial-marine plains of the Rio Grande do Norte: a geosystemic approach
}

\author{
Guedes $^{1}$, D. R. da C.; Santos $^{2}$, N. M; Cestaro 3 , L. A.; \\ dayane.geo10@hotmail.com
}

\section{Resumo}

As planícies flúvio-marinhas são sistemas ambientais importantes no contexto socioeconômico do Rio Grande do Norte por conta da sua dinâmica ambiental. A presente proposta teve como objetivo analisar a dinâmica geoambiental das Planícies Flúvio-marinhas do Estado, identificando os elementos e as interações que compõem essa unidade ambiental no contexto do Estado. Os procedimentos metodológicos utilizados para alcance dos objetivos foram levantamento de material cartográfico, revisão bibliográfica e trabalho de campo. Por apresentarem particularidades para cada porção do litoral (Setentrional e Oriental), principalmente por conta das diferentes influências climáticas e ocorrência de estuário negativo e positivo, respectivamente, para cada porção da costa litorânea, propõe-se a subdivisão destes sistemas em: Planícies Flúvio-marinha do Litoral Setentrional e Planícies Flúvio-marinha do Litoral Oriental

Palavras-chave: Planície flúvio-marinha, Rio Grande do Norte, sistemas ambientais.
\end{abstract}

\begin{abstract}
The fluvial-marine plains are important environmental systems in the socioeconomic context of Rio Grande do Norte, on account of its environmental dynamics. This paper aimed to analyze the geo-environmental dynamics of Fluvio-marine Plains of Rio Grande do Norte state, identifying the elements and theirs interactions. The methodological procedures used to achieve the objectives were lifting cartographic material, literature review and fieldwork. According to the characteristics of each portion of the coast (North and East), it is proposed the subdivision of these systems: Northern Coast Fluviomarine Plains and Eastern Fluvio-marine Plains, mainly due to the different climatic influences and occurrence of negative estuary and positive, respectively, for each portion of the coast.
\end{abstract}

Keywords: Tidal river plain, Rio Grande do Norte, environmental systems.

\section{INTRODUÇÃO}

A localização geográfica influenciará na diversidade das características e interações dos sistemas ambientais, imprimindo particularidades pela atuação dos fatores endógenos e exógenos que atuam na superfície terrestre. Para analisar a dinâmica dentro destes sistemas e suas interações com outros, são instituídas unidades ambientais que agrupam o maior número de geofácies inerentes a um determinado sistema ambiental.

Segundo Christofoletti (1999), os sistemas ambientais representam unidades organizadas na superfície terrestre, de modo que a espacialidade se torna uma das suas características inerentes. A organização desses sistemas vincula-se com a estruturação e funcionamento de (entre) seus elementos, assim como resulta da dinâmica evolutiva.

Para compreender a dinâmica destes ambientes, suas potencialidades e fragilidades, considerando a ação humana é necessário identificar as relações existentes entre os meio físico e social. Sotchava (1978) destaca que o geossistema inclui, em si, as mudanças causadas por fatores econômicos e sociais, interligando-se com os conceitos de sistema ou complexo produtivo territorial. Neste

\footnotetext{
${ }^{l}$ Dayane Raquel da Cruz Guedes, Programa de Pós Graduação em Geografia, Universidade Federal do Rio Grande do Norte, Natal - RN, Brasil.

${ }^{2}$ Nayara Marques Santos, Programa de Pós Graduação em Geografia, Universidade Federal do Rio Grande do Norte, Natal - RN, Brasil.

${ }^{3}$ Luiz Antonio Cestaro, Departamento de Geografia, Universidade Federal do Rio Grande do Norte, Natal - RN, Brasil.
} 
sentido a abordagem proposta por ele permiti considerar os elementos antrópicos e físicos na discussão da dinâmica nos sistemas ambientais.

Neste contexto Cestaro et al. (2007) propuseram para o Estado do Rio Grande do Norte um sistema de classificação das unidades ambientais que servisse de base para o Zoneamento Geoambiental. O Estado foi compartimentando em 9 regiões naturais, 17 geossistemas e 35 geofácies, entre as regiões naturais estão: Depressão Sertaneja, Planalto da Borborema, Planalto Residual, Morros basálticos isolados, Tabuleiro, Chapada, Planície Costeira, Planície Flúvio-marinha e Planície Fluvial e Lagunar.

As Planícies Flúvio-marinhas constituem-se como ambiente de contato entre os sistemas deposicionais continentais e marinhos de intensos processos físicos, químicos, geológicos e biológicos, alto teor de nutrientes e produtividade, importantes áreas para o desenvolvimento de atividades humanas de caráter econômico e caracterizam-se como ambientes frágeis e vulneráveis.

No Rio Grande do Norte a utilização destas áreas para a instalação de salinas é muito expressiva, posto que as condições naturais destes ambientes no Estado condicionam a produção de sal em larga escala, importante produto para economia local. O presente trabalho tem como objetivo analisar a dinâmica geoambiental das Planícies Flúvio-marinhas do Rio Grande Norte, identificando os elementos e as interações que compõe essa unidade ambiental no contexto do Estado.

\section{METODOLOGIA}

A pesquisa partiu da abordagem geossistêmica para análise das planícies flúviomarinhas, esta abordagem consiste que os elementos que compõe a dinâmica de um sistema ambiental estabelecem relações entre si. Christofoletti (1999) elabora o esquema de interação dentro de um geossistema, onde a geomorfologia, clima, hidrologia, vegetação, solo, fauna e ação antrópica formariam um complexo essencialmente dinâmico. Para alcance dos objetivos da proposta, foram utilizados os seguintes procedimentos metodológicos:

- Levantamento e análise do material bibliográfico referente a dinâmica ambiental das planícies flúvio-marinhas em Miranda, Castro e Kjerfve (2002); Suguio (2003) e Rosseti (2008); as características físicas do Rio Grande do Norte no Projeto RADAMBRASIL - Folhas SB 24/25. Guajaribe/Natal (1981); Nunes (2006) e CPRM - Geodiversidade do Rio Grande do Norte $(2010$

- Levantamento e análise do material Cartográfico e de Sensoriamento Remoto, para identificar as áreas de ocorrência das planícies no Estado e subsidiar a caracterização físicas destes ambientes;

- Trabalho de campo para registro fotográfico das atividades humanas desenvolvidas na área e validação de dados obtidos através do levantamento bibliográfico;

- Interpretação e análise das informações obtidas através das informações coletadas na bibliografia e em campo; 


\section{RESULTADOS E DISCUSSÃO}

No Rio Grande do Norte, a planície flúvio-marinha se estende pelo litoral setentrional nos municípios São Bento do Norte, Caiçara do Norte, Galinhos, Guamaré, Macau, Pendência, Carnaubais, Porto do Mangue, Areia Branca, Mossoró e Grossos, e pelo litoral oriental envolvendo Canguaretama, Baía Formosa, Tibau do Sul, Arês, Goianinha, Senador Georgino Avelino, Nísia Floresta, Macaíba, Natal, São Gonçalo do Amarante e Extremoz (Figura 01).

A planície flúvio-marinha possui características diferenciadas ao longo do litoral. De acordo com Nunes (2006), os mangues apresentam em maiores extensões no litoral oriental sul, enquanto que no litoral norte, a vegetação de mangue ocupa pequenas áreas. Prates, Gatto e Costa (1891) colocam que no litoral oriental a rede de drenagem apresenta-se com maior frequência e é constituída por cursos de águas perenes, fazendo com que tenha mais área de ocorrência de planície flúvio-marinha. Já o litoral norte possui poucos estuários, mas são áreas de acumulação flúviomarinha de maiores extensões, onde os índices pluviométricos são concentrados em poucos meses do ano (dezembro a maio). Devido aos fatores climáticos, os estuários se tornam negativos/hipersalinos, atingindo valores de salinidade acima de 40 g.L. $\mathrm{L}^{-1}$, favorecendo assim a produção de sal no estado (MIRANDA et al., 2004; SILVA et al., 2009; COSTA et al., 2010).

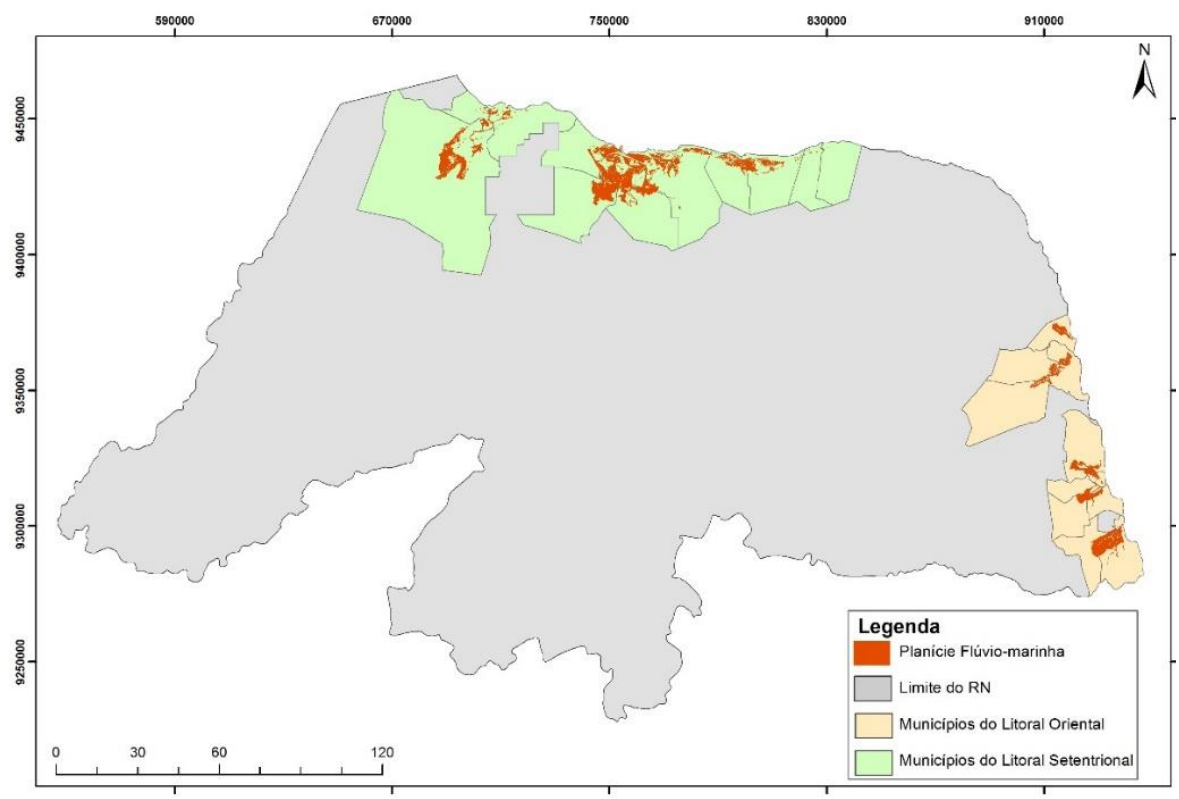

Figura 01: Mapa de localização das planícies flúvio-marinhas no RN. Base: IBGE, 2010; IDEMA, 2007

Segundo Miranda, Castro e Kjerfve (2002) os estuários negativos ocorrem quando a soma dos volumes de precipitação e descarga fluvial são menores que o volume de água transferido para a atmosfera pelo processo de evaporação. O processo inverso, quando a soma dos valores de precipitação e descarga fluvial são maiores que a taxa de evaporação, classifica-se como estuários positivos. 
As duas bacias hidrográficas mais importantes do Estado do Rio Grande do Norte estão localizadas no litoral setentrional, a do rio Piranhas-Açu e do rio Apodi-Mossoró. O rio PiranhasAçu é o mais importante, estando represado pela Barragem Engenheiro Armando Ribeiro Gonçalves (VITAL, 2006). As bacias dos rios Ceará-Mirim, Potengi, Trairi, Jacu e Curimataú (Litoral oriental) apesar de em maior número, são de menor porte, contribuindo com reduzido aporte fluvial de sedimentos para a região (VITAL, 2006). As Planícies Flúvio-marinhas no litoral setentrional são mais extensas do que no oriental.

Portanto, as planícies flúvio-marinhas no Estado, constituem de sedimentos trabalhados pelo fluxo hidrodinâmico continental e marinho. Sendo uma unidade geoambiental que apresenta características distintas entre o litoral setentrional e oriental. Todo sistema ambiental é constituído de elementos naturais que com as trocas de fluxo e energia, sustentam a dinâmica do mesmo. Geologia, relevo, solos, vegetação e clima são alguns destes elementos que interagem entre si e com as atividades humanas, constituem e influenciam diretamente o sistema.

As Planícies Flúvio-marinhas do Rio Grande do Norte estão assentadas, geologicamente, sobre a Bacia Sedimentar Potiguar, em área de ocorrência da Formação Barreiras (CPRM, 2010). Áreas caracterizadas por grau diagenético fraco, sedimentos arenosos-argilosos, intercalações silticas e conglomeráticas, originadas em ambiente continental fluvial e deltaico, intercalados com registro de correntes de lama e areia e flutuações climáticas (GOMES. et. al., 1981).

No que se refere ao relevo, são áreas planas resultantes da combinação de processos de acumulação fluvial e marinha, geralmente sujeitas a inundações periódicas (PRATES, GATTO, COSTA, 1981). Este tipo de relevo favorece o processo de acumulação de sedimentos. No litoral setentrional as áreas de planície são mais extensas, comparadas ao oriental. De acordo com CPRM (2010) são áreas cuja a declividade varia de 0 a $3^{\circ}$ e amplitude topográfica é zero.

As áreas sofrem influência dos climas semiárido, subúmido e úmido. O clima subúmido a semiárido apresenta elevada temperatura média entre $26^{\circ} \mathrm{C}$ a $27^{\circ} \mathrm{C}$ e totais pluviométricos que estão registrados entre 800 e 1.200 mm anuais. O clima úmido apresenta a precipitação anual está entre 2.000 e $2.500 \mathrm{~mm}$, caracterizada pela úmida mais intensa no litoral (AZEVEDO, MOREIRA, 1987). No litoral setentrional, predominam as precipitações com valores entre 600 e $800 \mathrm{~mm}$, com valores inferiores a $600 \mathrm{~mm}$ na sua parte central, alcançando núcleos ligeiramente inferiores a 500 mm. No litoral oriental os totais de precipitação anual variam entre 800 e 1.600 mm (CPRM, 2010).

O sistema flúvio-marinha ocorre nas desembocaduras dos rios: Apodi-Mossoró, Piranhas-Açu, Camurupim, Galinhos, Ceará-Mirim, Potengi, Trairi, Jacu e Curimataú. De acordo com a CPRM (2010) os recursos hídricos superficiais do estado do Rio Grande do Norte se 
apresentam em dois contextos climáticos distintos: recursos hídricos superficiais das regiões climáticas semiáridas (intermitentes) e recursos hídricos de regiões climáticas úmidas (perenes).

Nestas áreas ocorrem os Gleissoslos Sálicos, predominantes nas planícies do litoral setentrional e os Solos Indiscriminados de Mangue no litoral oriental. Os Solos Indiscriminados de Mangue compreendem os solos não ou muito pouco desenvolvidos, gleizados, mal ou muito mal drenados, com alto conteúdo de sais provenientes da água do mar e composto de enxofre, que se formam nessas áreas baixas e alagadas (SOUZA et al., 1981).

Os Solonchack, são solos salinos que apresentam altas concentrações de sais de sódio, cálcio, magnésio e outros. Extremamente rasos, apresentam um horizonte sálico e crostas de sais (Figura 05) na superfície no período seco (SOUZA et al., 1981). Estes solos são encontrados nas planícies do litoral setentrional, recebendo influência das marés em altitudes acima de 2 metros (NUNES, 2006). A vegetação encontrada na área é caracterizada por Salgado, Filho e Gonçalves (1981) como Áreas de Formação Pioneira, são ambientes dependentes da sedimentação do terreno pela deposição aluvial ou marítima e das oportunidades ecológicas no transporte de sementes das comunidades envolventes. Ocorrência de formações arbóreas, representada pelo mangue e herbáceas, representada pelas espécies halófitas.

Estas áreas são marcadas pela presença de caranguejos, siris, goiamuns e aratus. A abundância de algas microscópicas é o principal motivo para alta produtividades nas áreas de mangues das planícies, servindo de alimento para animais menores. Dentre os comedores de algas microscópicas estão a ostra, o mexilhão, o sururu e o camarão nativo. Há também os organismos que se alimentam dos zooplânctons, constituídos por microcrustáceos e larvas de molusco (NUNES, 2006).

\subsection{INTERAÇÕES NO SISTEMA}

A dinâmica de um sistema é regida pela entrada de fluxos de energia e matéria, fazendo com que os elementos possam interagir entre si. Christofoletti (1999) elabora o esquema de interação dentro de um geossistema, onde a geomorfologia, clima, hidrologia, vegetação, solo, fauna e ação antrópica formariam um complexo essencialmente dinâmico. Neste contexto, para analisar o sistema de Planície Flúvio-marinha do Rio Grande do Norte, é preciso considerar o clima como ponto de partida para análise.

As diferentes características climáticas para os litorais setentrional e oriental influenciam diretamente nas formas de ocorrência e nas condições das planícies para os diferentes setores. No setentrional, o clima subúmido a semiárido influencia no regime dos rios, caracterizado por precipitações com valores entre 500 e $800 \mathrm{~mm}$ e temperaturas anuas médias entre $26^{\circ} \mathrm{C}$ e $27^{\circ} \mathrm{C}$ (AZEVEDO e MOREIRA, 1987). 
Onde nas regiões predominantemente semiáridas os rios são de caráter intermitente e secam completamente no período de estiagem, condicionados na maior parte por um substrato geológico/hidrogeológico composto por rochas cristalinas de baixa porosidade e permeabilidade e praticamente sem regolitos ou solos capazes de reter águas de chuva, favorecendo os escoamentos superficiais (CPRM, 2010).

Tais condições refletem na ocorrência de volumes menores de precipitação e descarga fluvial e altas taxas de evapotranspiração, caracterizando os estuários dessa porção como negativos e hipersalinos. As Planícies Flúvio-marinhas formadas pelos rios Apodi e Piranhas-Açu se estendem até $35 \mathrm{~km}$ para o interior (PRATES, GATTO e COSTA, 1981). Nas proximidades do litoral, ambas são ocupadas por salinas, a influência do mar nos estuários desses rios é maior do que aquela efetivada no rio Jaguaribe, razão pela qual, neles existem condições mais propícias para extração de sal (PRATES, GATTO e COSTA, 1981). A produção sal nesta região caracteriza-se como importante atividade econômica para o Estado e importante produto no âmbito nacional.

O elevado teor de sal nesse ambiente constitui limitações para o desenvolvimento de vegetações mais arbóreas, ocorrendo nessas áreas espécies halófitas, de forma mais esparsa ou ausência de vegetação. Caracterizando-se também, os solos da área, por apresentarem altas concentrações de sais de sódio, cálcio, magnésio e outros, sendo extremamente rasos, apresentam um horizonte sálico e crostas de sais na superfície no período seco (NUNES, 2006). A fauna nessas áreas é inexpressiva.

No litoral oriental, a influência do clima sub-úmido imprime uma outra dinâmica as planícies deste setor. Caracterizados por precipitações médias (entre 1.000 e 1.500mm/ano), especialmente na região costeira oriental do estado, ocorrem águas superficiais drenadas nos trechos médios e baixos dos principais rios e riachos costeiros. Condicionadas pelo fluxo de base desenvolvido pelo redirecionamento do escoamento subterrâneo e ressurgência das águas subterrâneas do aquífero Barreiras nos vales, tornando esses rios e riachos perenes (CPRM,2010).

A umidade alta do ar, os volumes consideráveis de precipitação e descarga fluvial apresentam-se maiores que as taxas de evapotranspiração, caracterizando as planícies desta porção como estuários positivos. Fatores que não favoreceram a produção de sal na região. Atualmente nessas áreas são desenvolvidas atividades voltadas para o cultivo do camarão (carcinicultura). Desta maneira os solos destas áreas (Solos Indiscriminados de Mangue) apresentam níveis moderados de sal, ocorrência de matéria orgânica, proveniente de decomposição da vegetação de mangue e da intensa atividade biológica produzida pela fauna (SOUZA et al., 1981).

A fauna é mais expressiva, com a presença de caranguejos, siris, goiamuns, aratus, abundância de algas microscópicas e microcrustáceos (NUNES, 2006). Devido as condições 
ambientais favoráveis a vegetação apresenta um porte mais arbóreo. Presença de espécies características como o Rhizophora mangle L. (mangue vermelho); Laguncularia racemosa (L.) C.F. Gaert (mangue branco), Avicennia schaueriana Stapf \& Leechm. ex Moldenke (mangue língua de vaca) e A. germinans L (mangue preto) (SALGADO, FILHO e GONÇALVES, 1981).

$\mathrm{Na}$ interface hidrologia - geologia (tanto para o litoral setentrional quanto oriental), caracterizam-se pela presença de aluviões, com areias finas a grosseiras, incluindo cascalhos e argilas, sedimentos com bom potencial hídrico. Nas áreas mais secas constituem a única opção para obtenção de água (BARROS et al., 1981). Ocorrência também de coberturas coluviais e eluviais, constituídas de areias siltico-argilosas, localmente laterizadas, que apresentam potencial hidrogeológico muito variável (fraco a bom), em função da posição que assumem nas diferentes bacias, em relação ao teor de argila, o principal condicionador do fluxo de água no seu interior (BARROS et al., 1981).

O relevo plano destes ambientes favorece a acumulação dos sedimentos carreados pela drenagem do rio (desde as nascentes, nas áreas mais elevadas), contato deste com o ambiente marinho e a diluição da água do mar com a do rio. Quanto maior a extensão da planície para o interior do continente, maior o avanço da maré sobre o terreno. As interações dentro do sistema de Planícies Flúvio-marinha sofrem influência direta das condições climáticas, que produzem características distintas para alguns elementos, em cada porção do litoral setentrional (Figura 02) e oriental (Figura 03).

Ainda no contexto das interações, as planícies flúvio-marinhas além de conter interrelações entre os seus componentes físicos, estabelece relações com sistemas ambientais vizinhos. No Rio Grande Norte está unidade ambiental mantém relação com os Tabuleiro Semiárido Interiorano, Tabuleiro Costeiro Semiárido, Tabuleiro Sub-úmido Oriental, Planície Costeira e Planície Fluvial e Lacustre, baseados na taxonomia proposta por Cestaro et al. (2007).

Cavalcanti (2004) acrescenta que essa unidade é considerada aberta no que se diz respeito ao transporte de matéria e energia, onde o "input" (transporte de matéria para dentro do sistema), sua reciclagem e posterior exportação (output), são controladas por fatores físicos (marés e precipitações) e fatores biológicos (atividades da fauna e decomposição animal e vegetal).

Assim, no litoral setentrional os sistemas que está nas adjacências são os tabuleiro semiárido interiorano, tabuleiro costeiro semiárido, planície costeira e planície fluvial e lacustre. Já no litoral oriental as unidades vizinhas são o tabuleiro sub-úmido oriental, planície costeira e planície fluvial e lacustre. Ambas apresentam características semelhantes de interação.

As redes de drenagens dos tabuleiros são responsáveis pelo transporte de sedimentos de maior fração, que serão carreados para a planície fluvial e lacustre. Ao chegar no litoral, o fluxo 
hídrico é lento, favorecendo a deposição de sedimentos de menor fração, a argila, o principal sedimento que forma a planície flúvio-marinha. A planície costeira também tem uma importante influência na deposição de partículas finas, que são efetuados pelos canais de maré, durante a maré cheia. E serve como uma barragem natural para evitar a erosão da linha costeira pela ação do mar.

Também ocorre a interação na interface entre a planície flúvio-marinha com o oceano. Pois o manguezal é considerado um berçário ecológico, por ser onde muitas espécies vivem, reproduzem e se alimentam, ocasionando intensa atividade biológica, produzindo nutrientes e matéria orgânica para sustentação da biodiversidade. E durante a maré cheia, algumas espécies de peixes vem até os manguezais para depositar as ovas, servindo de refúgio para as espécies, fugindo de possíveis predadores.

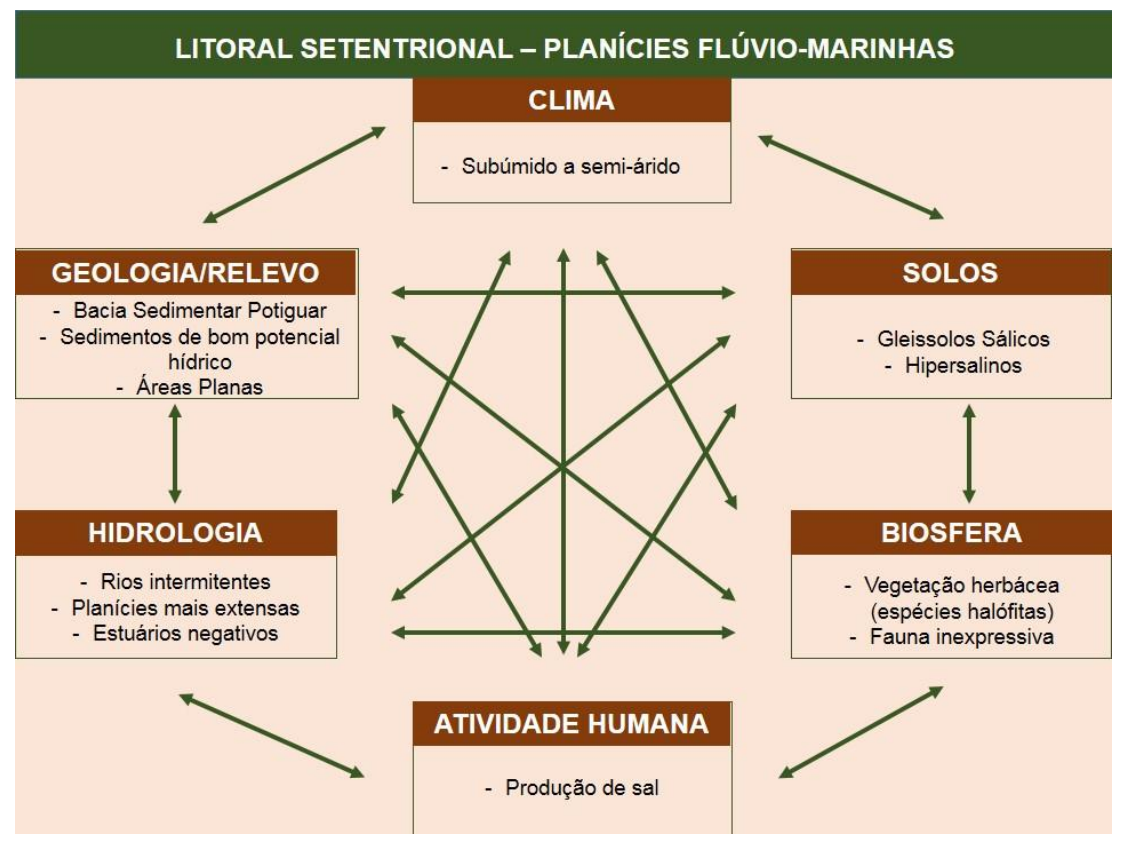

Figura 02: Esquema de interação dos elementos no Litoral Setentrional. Fonte: Adaptado de Christofoletti, 1999; RADAM, 1981; CPRM, 2010; NUNES, 2006. 


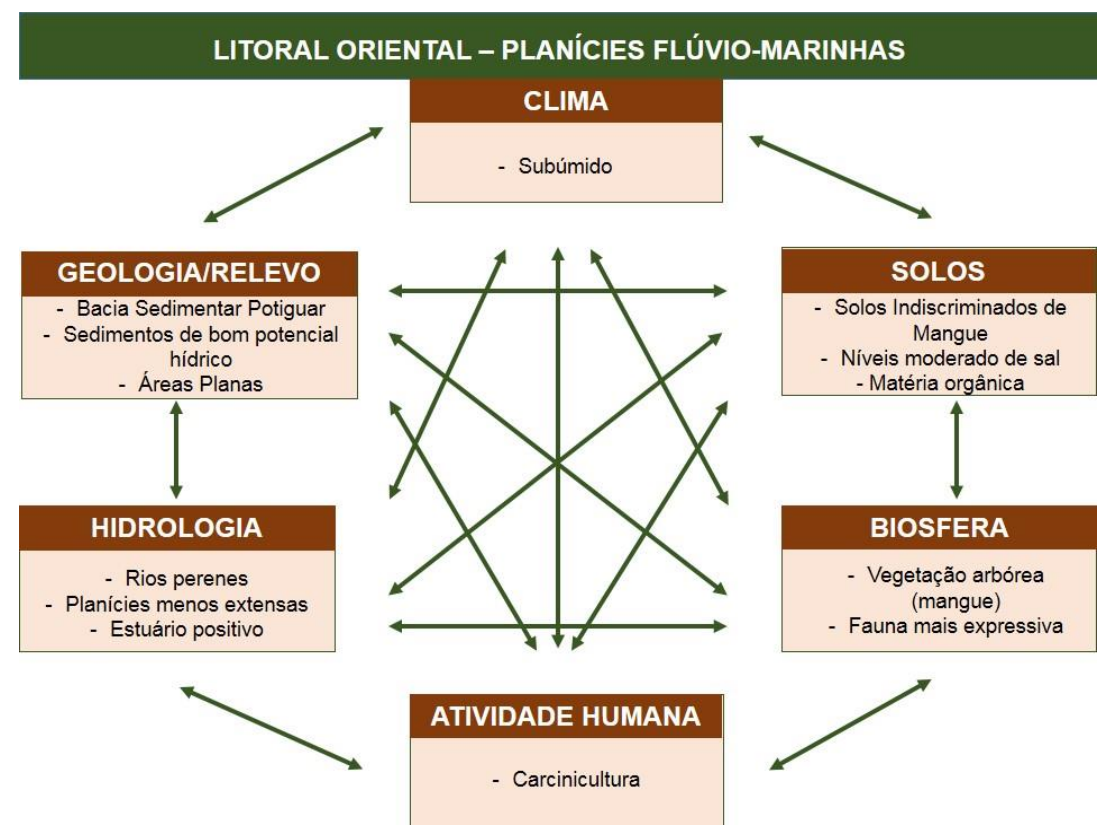

Figura 03: Esquema de interação dos elementos no Litoral Oriental. Fonte: Adaptado de Christofoletti, 1999; RADAM, 1981; CPRM, 2010; NUNES, 2006.

\section{CONSIDERAÇÕES FINAIS}

Em decorrência do baixo nível de aproveitamento agrícola na área de flúvio-marinha por serem ambientes com sedimentos inconsolidados, esta unidade possui uma potencialidade natural, que adquire uma significativa importância como fonte de recursos utilizados pela população local, contribuindo no suplemento de alimentos para as comunidades residentes. E proporciona uma intensa atividade biológica, que caracteriza ser um ambiente de elevada produtividade. No litoral setentrional, a hipersalinidade é uma potencialidade do ponto de vista da ação antrópica, através da construção de salinas. Porém, essa hipersalinidade se torna um fator limitante para o desenvolvimento da vegetação de mangue. Mesmo apresentando áreas de maiores acumulação flúvio-marinha, no entanto, apresenta pequenos bosques de mangue.

Por apresentarem particularidades para cada porção do litoral (Setentrional e Oriental), principalmente por conta das diferentes influências climáticas e ocorrência de estuário negativo e positivo, respectivamente, para cada porção da costa litorânea, propõe-se a subdivisão destes sistemas em: Planícies Flúvio-marinha do Litoral Setentrional e Planícies Flúvio-marinha do Litoral Oriental. Portanto, o aprofundamento do conhecimento das fragilidades desses ambientes, torna importante para o planejamento e também para a preservação das áreas de manguezais. Principalmente, porque, são áreas tidos por lei, que devem ser preservadas, por serem ambientes dinâmicos e prestar diversos serviços ecossistêmicos, tanto para o equilíbrio dinâmico do sistema, quanto para sociedade. 


\section{REFERÊNCIAS}

AZEVEDO, L. M. P.; MOREIRA, R. de C. Geomorfologia. In: Projeto RADAM - Brasil. IBGE. 1981.

BARROS, M. J. G.; RIBEIRO, A. G.; LIMA, E. A.; FONSÊCA, R. A. da. Potencial de Recursos Hídricos. In: Projeto RADAM - Brasil. IBGE. 1981.

CAVALCANTI, A. P. B. Análise integrada das unidades paisagísticas na planície deltaica do rio Parnaíba-Piauí/Maranhão. Mercator, n. 03, v. 06, 2004.

CESTARO, L. A.; ARAÚJO, P. C.; MEDEIROS, C. N.; CISNEIROS, R.; ARAÚJO, L. P. Proposta de um sistema de unidade geoambientais para o Rio Grande do Norte. Anais. In: XII Simpósio Brasileiro de Geografia Física Aplicada, Anais... Natal, 2007.

CHRISTOFOLETTI, A. Modelagem de sistemas ambientais. São Paulo: Edgard Blücher, 1999.

COSTA, D. F. S.; DE MEDEIROS ROCHA, R.; CÂNDIDO, G. A. Perfil de sustentabilidade e uso dos recursos naturais em salinas solares no estuário do Rio Apodi-Mossoró (RN). In: GESINALDO A. CÂNDIDO, G. A. (org.), Desenvolvimento Sustentável e Sistemas de Indicadores de Sustentabilidade: formas de aplicações em contextos geográficos diversos e contingências específicas. Editora da Universidade Federal de Campina Grande, 2010, p. 401 - 426.

CPRM. Serviço Geológico Brasileiro. Geodiversidade do Estado do Rio Grande do Norte. Pedro Augusto dos Santos Pfaltzgraff (Org.). Recife: CPRM, 2010.

GOMES, J. R. de C.; GATTO, C. M. P. P.; SOUZA, G. M. C. de; LUZ, D. S. da; PIRES, J. de L.; TEIXEIRA, W. Geologia. In: Projeto RADAM - Brasil. IBGE. 1981.

MIRANDA, L.B.; CASTRO, B.M.; KJERFVE, B. Princípios de oceanografia física de estuários. São Paulo: Editora da Universidade de São Paulo, 2002, 424 p.

NUNES, E. Geografia Física do Rio Grande do Norte. Natal: Imagem Gráfica, 2006, 114p.

PRATES, M.; GATTO, L.C.S.; COSTA, M.I.P. Geomorfologia. In: Projeto RADAM - Brasil. IBGE. 1981.

ROSSETI, D. de F. Ambientes Costeiros .2008. In: FLORENZANO, T.G. (2008). Geomorfologia: conceitos e tecnologias atuais. São Paulo: Oficina de Textos. 317 pp.

SALGADO, O. A.; FILHO, S. J.; GONÇALVES, L.M.C. Vegetação: as regiões fitoecológicas, sua natureza e seus recursos econômicos. Estudo fitogrográfico. In: Projeto RADAM - Brasil. IBGE. 1981.

SILVA, A. M. A.; BARBOSA, J. E. L.; MEDEIROS, P. R.; ROCHA, R. M.; LUCENA FILHO, M. A.; COSTA, D. F. S. Zooplankton (Cladocera and Rotifera) variations along a horizontal salinity gradient and during two seasons (dry and rainy) in a tropical inverse estuary (Northeast Brazil). Pan-American Journal of Aquatic Sciences, v. 4, n. 2, p. 226-238, 2009. 
SOTCHAVA, V. B. Por uma teoria de classificação dos geossistemas de vida terrestre. Biogeografia. São Paulo, n. 14, p. 01-21, 1978.

SOUZA, C. G.; VIANA, C. D. B.; WAKI, M.; COSTA, V. S. da. Pedologia. In: Projeto RADAM Brasil. IBGE. 1981.

SUGUIO, K. Geologia Sedimentar. São Paulo: Blucher, 2003. 383p.

VITAL, H. Erosão e progradação do litoral do Rio Grande do Norte. In: MUEHE, D. (Org.). Erosão e progradação do litoral brasileiro. Brasília: Ministério do Meio Ambiente. 2005, 159$176 \mathrm{p}$.

\section{AGRADECIMENTOS}

Agradecemos a Coordenação de Aperfeiçoamento de Pessoal do Nível Superior pela concessão da bolsa de mestrado através do Programa de Pós-graduação em Geografia da Universidade Federal do Rio Grande do Norte.

Recebido em: 14/08/2016

Aceito para publicação em: 01/10/2016 